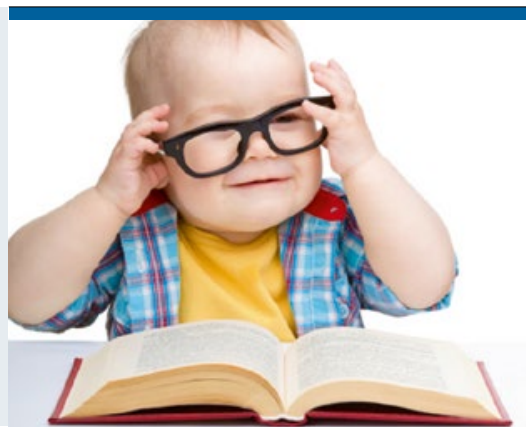

Für Eltern, Kinder und Kinderärzte

\title{
Kinderbuch-Empfehlungen
}

Diesmal zu den Themen Mut und Wut von Dipl.-Psych. Wiebke Claßen

\section{Persönliche Herausforderungen}

- Maus, Schnecke, Frosch und Spatz sitzen am Ufer des Weihers und beschließen einen Wettkampf zu machen, wer von innen am mutigsten ist. Die Maus taucht durch den See, der Frosch frisst eine Seerose und die Schnecke umrundet ihr Haus, jeder ist auf seine Weise sehr mutig. Nur der Spatz sagt nach längerem Nachdenken: „Ich mach” nicht mit."

Die anderen sind verdutzt, denn vom frechen Spatz hatten sie etwas anderes erwartet, aber schließlich jubeln sie dem Spatz zu: "Ja, das ist Mut."

Warum dieses Buch? Allein die Bilder in diesem Buch sind wunderschön und lassen sich immer wieder betrachten. Jeder stellt sich in dem Buch seiner persönlichen Herausforderung und wird von den anderen für seine Leistung respektiert. Den größten Mut zeigt derjenige, der Nein sagt und nicht mitmachen möchte. Kinder werden durch dieses Buch darin bestärkt, dass es auch mutig ist, etwas nicht mitzumachen und dass man zu sich selber stehen darf. Sehr empfehlenswert!

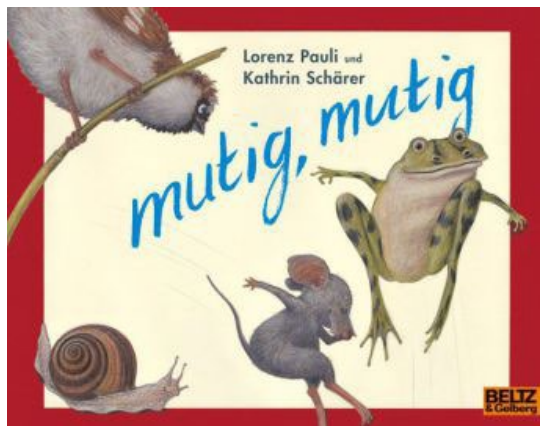

Lorenz Pauli, Kathrin Schärer

\section{mutig, mutig}

Ab 4 Jahren

Beltz

$6,50 €$

\section{Wütende und wilde Kerle}

— Der kleine Max, der eines Abends seinen Wolfspelz trägt und Unfug anstellt, wird von seiner Mutter ohne Essen ins Bett geschickt. Er begibt sich daraufhin auf eine Traumreise ins Land der wilden Kerle. Er zähmt die wilden Kerle allein mit seinem Blick und wird ihr König. Gemeinsam machen sie nun Krach und Unfug, bis es Max reicht und er sich nach jemandem sehnt, der inn lieb hat. Wieder zuhause angekommen, steht ein warmes Essen in seinem Zimmer.

Warum dieses Buch? 40 Jahre ist dieses Buch alt und doch bleibt es zeitlos, denn es beschreibt einen Zustand den alle Kinder kennen: wütend sein, mit den Augen rollen, Brüllen und die Krallen ausfahren. Kinder können sich mit Max und den wilden Kerlen identifizieren. Es wird gezeigt, dass Kinder auch mal wütend sein dürfen. Indem der Autor Max zum König der wilden Kerle macht, zeigt er wunderbar, dass Kinder auch in ihrer Wut Einfluss auf ihre Gefühle haben können. Die kurzen Sätze und die Bilder lassen den Kindern Freiraum für Phantasie.

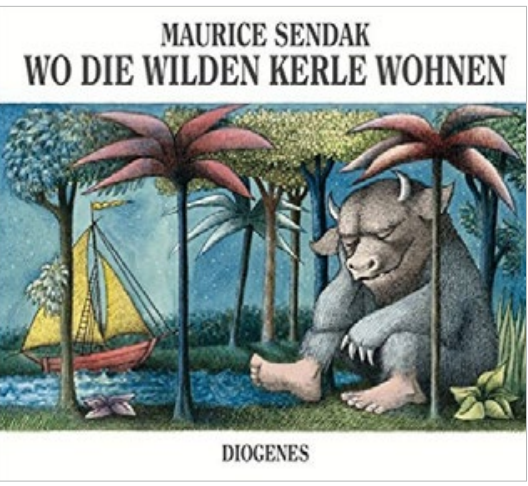

Maurice Sendak

Wo die wilden Kerle wohnen

Ab 5 Jahren

Diogenes

$20 €$

\section{Anders abhängen}

— Stellaluna ist ein kleines Flughundmädchen, das eines Nachts von seiner Mutter getrennt in einem Vogelnest landet und sich von nun an wie ein Vogelkind verhalten soll: Insekten fressen, tagsüber wach sein und nicht kopfüber am Nestrand hängen. Stellaluna bemüht sich sehr, nicht unangenehm aufzufallen. Eines Tages begegnet sie einem anderen Flughund, der ihr sagt, dass ihre Bedürfnisse ganz richtig sind und sie ruhig bei Tageslicht an den Hinterfüßen hängen darf. Die Freundschaft zu den Vo-

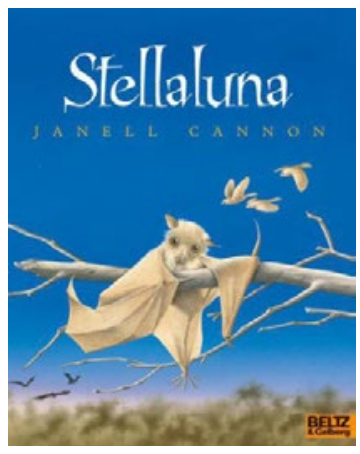

Janell Cannon Stellaluna Ab 4 Jahren Beltz $6,50 €$ gelkindern bleibt trotzdem erhalten.

Warum dieses Buch? Es geht um Freundschaft trotz erheblicher Unterschiede und um Anpassung und Hilfe in schwierigen Situationen. Ein Zitat aus dem Buch beschreibt es am besten: „Wie können wir so verschieden sein und uns doch so ähnlich fühlen?"... Wie können wir so verschieden fühlen und doch so ähnlich sein?... Ich glaube, das ist ein großes Geheimnis." 